\title{
Influence of steel slag stabilized mixtures on pavement stress-strain characteristics
}

\author{
[ Ivana Barišić ]
}

\begin{abstract}
Due to the limitations of empirical methods in pavement structure design, analytical method is applied in order to estimate influence of new materials on pavement stress and strain state. Measured modulus of elasticity for cement stabilized base layer with gravel and steel slag are used for stress and strain calculation using BISAR software. Results show that adding steel slag to cement stabilized mixes with $2 \%$ and $4 \%$ cement content result in subgrade stress decrease by about $11 \%$ and $6 \%$ respectively and strain decrease by about $13 \%$ and $7 \%$ respectively.
\end{abstract}

Keywords-pavement, elastic moduli, analitical design, steel slag, stress, strain

\section{Introduction}

In practice, most of the pavement structural designs are made using empirical methods. These methods are based on the results of pavement performance systematic observation. Observations are usually carried out on the existing road sections, on particular for this purpose built test sections, or more recently, on specially constructed sections for accelerated experimental loads testing. Some of the first design curves based on road tests became available in 1960s [1]. Due to its efficient and easy operation features [2] these methods are very widespread in engineering practice although having some limitations and disadvantages.

Limitations in empirical approach of pavement design are becoming more apparent primarily due to the increasing traffic trend in highways in terms of volume and axle loads, since the construction and characteristics of heavy vehicles are differing from the vehicles existing at the time of the formation of empirical methods. Second problem arise with the application of new materials, particularly waste materials and industrial by-products which characteristics and behaviour when inbuilt in pavement layer are still insufficiently explored. Therefore, there is a need for a more flexible approach in the design of pavement structures by applying an analytical methods.

Basis of the analytical design is the use of mathematical models to calculate the stresses and strains in pavement structure as a response to vehicle load. Calculated stress and strain are used for pavement damage evaluation and consequently pavement life estimation. There are two approaches in analytical pavement design. First one is layered elastic model using a semi-infinite multi-layer elastic system for pavement approximation.

University of Osijek, Faculty of Civil Engineering Osijek Croatia
Second one is finite element model approximating pavement also by semi-infinite multi-layer elastic system, but each layer is also divided vertically and horizontally in the network system. The input data for both methods are similar: material properties expressed as Young's modulus E and Poisson's ratio v, thickness of each layer and load. However, material properties in finite element model are treated closer to visco-elastic or plastic, but to elastic state. Material anisotropy and thin interlayer in pavement responses can also be taken into account using finite element method [2]. Unlike the layered elastic model, finite element model can also be used for simulating moving or dynamic load. Output data are the same from both models: stress, strain and displacements.

Analytical methods for pavement structure analysis are used for studying the effect of axle load increase, pavement layers thicknesses increase and the variation in temperature and elastic modulus of pavement layers, on the overall pavement life [3]. In [4], Split Mastic Asphalt (SMA) mixtures containing polymers and fibers are investigated using mechanistic-empirical approach to determine the effect of different additives in increasing the service life of the pavement and reduction of the pavement layers thickness.

In this study, effect of cement stabilized steel slag base layer on pavement stress and strain level is investigated. For evaluation of stress and strain state, elastic modulus were measured for mixtures containing various cement content and different aggregate material: natural gravel and industrial byproduct steel slag. Using measured input data, stress and strain were calculated using Bitumen Stress Analysis in Roads (BISAR) software developed in 1989 year by Shell Petroleum Company [5].

For stress and strain analysis, three critical points in pavement structure were analysed: bottom of the asphalt and cement stabilized base layers for tensile state and upper subgrade surface for compressive state. Since elastic modulus of the asphalt is highly affected by pavement temperature [3], two seasons are analysed, winter and summer.

\section{Materials and methods}

\section{A. Materials characterization}

As a natural material, gravel from the river Drava were used. This is local material, gray-brown colour, with a grain size $\mathrm{D}_{50}=6 \mathrm{~mm}$ and a degree of non-uniformity $\mathrm{U}=\mathrm{d}_{60} / \mathrm{d}_{10}=20$. The maximum dry density and optimum water content defined by modified Proctor test according to the EN 13286-2:2010 for used gravel were $2.06 \mathrm{~g} / \mathrm{cm}^{3}$ and $4.71 \%$ respectively.

Steel slag from the landfill near the town of Sisak was used as substitute aggregate material. It is a combination of blast 
Proc. of the Third Intl. Conf. on Advances in Civil and Structural Engineering - CSE 2015

Copyright $(\odot$ Institute of Research Engineers and Doctors, USA .All rights reserved.

ISBN: 978-1-63248-057-6 doi: 10.15224/ 978-1-63248-057-6-46

furnace and electric furnace slag. A degree of non-uniformity of this material was $U=d_{60} / d_{10}=21.4$ and a grain size $D_{50}=5.5$ $\mathrm{mm}$. Grain size distribution curves are presented in Fig. 1.

As a binder, Portland cement of grade 32.5 (CEM II B/M (P-S) $32,5 \mathrm{R}$ ) was used as $2 \%$ and $4 \%$ of aggregate mass.

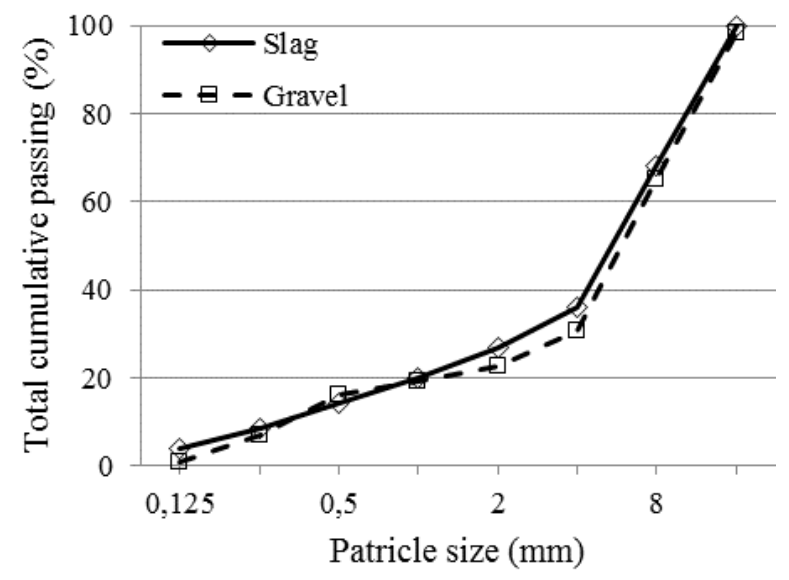

Figure 1. Particle-size distribution curves for used aggregate

\section{B. Measurement of moduli of elasticity}

Since the traffic load by its nature is cyclical, dynamic load, dynamic modulus of elasticity is used for stress-strain analysis.

Moduli of elasticity were measured on cement stabilized mixes (CSM) for pavement base layer varying the contents of binder (cement) and type of aggregate (gravel and steel slag). Table I gives the compositions of tested mixtures. Namely, the main influence on ultrasonic pulse velocity (UPV) measurement is that of aggregate type, percentage and maximum size and cement percentage [6] so in this study two aggregate types and two cement percentages were used.

TABLE I. COMPOSITION OF TESTED CEMENT-STABILIZED MIXTURES

\begin{tabular}{|c|c|c|c|}
\hline Mix ID & Cement [\%] & Gravel [\%] & Steel slag [\%] \\
\hline G2 & 2 & 100 & 0 \\
\hline S2 & 2 & 0 & 100 \\
\hline G4 & 4 & 100 & 0 \\
\hline S4 & 4 & 0 & 100 \\
\hline
\end{tabular}

Specimens were prepared at their respective optimum moisture content and maximum dry density according to EN 13286-50. The compacted specimens were $100 \mathrm{~mm}$ in diameter and $200 \mathrm{~mm}$ in height (cylindrical shape). The specimens were cured for 28 days in a chamber at controlled temperature $\left(20^{\circ} \mathrm{C}\right)$ and moisture (60\% relative humidity). For each mixture 6 identical specimens were prepared.

For better precision and less disturbance of measurement, transducer of $5 \mathrm{~cm}$ diameter and frequency of $45 \mathrm{kHz}$ was used in this study [6,7].
For every sample, measurement of transmission time were recorded and pulse transmission velocity was calculated using (1):

$$
\mathrm{v}=\mathrm{L} / \mathrm{T}
$$

where $\mathrm{v}$ is transmission velocity $(\mathrm{m} / \mathrm{s}), \mathrm{L}$ is transmission distance equal to sample length (m) and $\mathrm{T}$ is measured transmission time (s). UPV is determined as average of three measurements for every sample and dynamic moduli is calculated as an average of three measurement for six of the kind samples. Results of dynamic modulus of elasticity measurement are presented in Table II and they are used in stress-strain analysis.

Measuring the ultrasound pulse velocity is used according to EN 12504-4 to determine the dynamic modulus of elasticity. The dynamic modulus of elasticity was calculated using (2):

$$
\mathrm{E}=\rho v^{2}((1+v)(1-2 v)) /(1-v)
$$

where $\mathrm{E}$ is dynamic modulus of elasticity $\left(\mathrm{MN} / \mathrm{m}^{2}\right), \mathrm{v}$ is the ultrasound pulse velocity $(\mathrm{km} / \mathrm{s}), \rho$ is the density $\left(\mathrm{kg} / \mathrm{m}^{3}\right)$ and $v$ is Poisson's ratio. Measurement of ultrasound pulse velocity for moduli of elasticity calculation is presented on Fig.2.

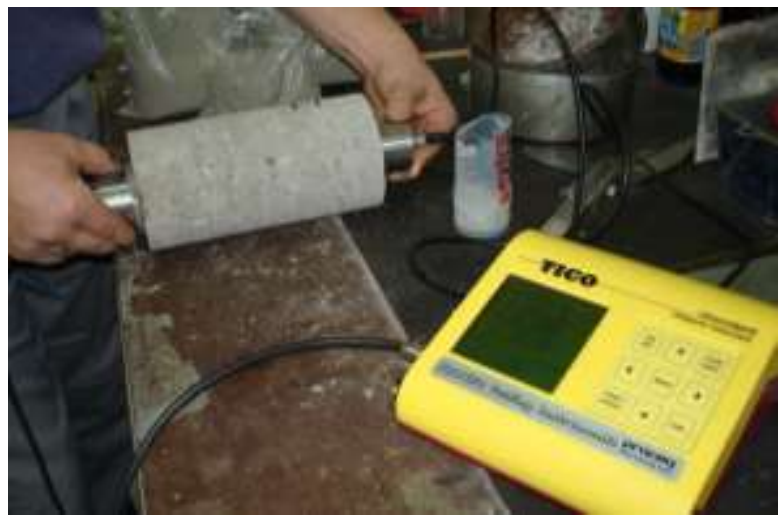

Figure 2. Measurement of ultrasound pulse velocity

\section{Stress and strain calculation}

For stress and strain calculation, software BISAR was used. It is a program for analysis of elastic multi-layer system consisting of horizontal layers of uniform thicknesses resting on a semi-infinite base or half space. Basic calculation assumptions are: layers extend infinitely in horizontal direction and materials are homogeneous, isotropic and elastic having a linear stress-strain relationship.

In the process of stress and strain analysis, single-axle load $(100 \mathrm{kN})$ was used.

For asphalt layers and subgrade, material characteristics were predicted based on engineering practice and available literature. The elastic modulus of asphalt layer is highly 
Proc. of the Third Intl. Conf. on Advances in Civil and Structural Engineering - CSE 2015

Copyright $(\odot$ Institute of Research Engineers and Doctors, USA .All rights reserved.

ISBN: 978-1-63248-057-6 doi: 10.15224/ 978-1-63248-057-6-46

affected by pavement temperature where the modulus decreases as the temperature increases [3]. For that reason, two seasons were analysed: summer and winter. Subgrade is predicted to be of compacted clay material with $\mathrm{CBR}=5 \%$.

In Table II, basic material properties and layer thickness are presented as an input parameters for stress-strain analyses.

TABLE II. INPUT PARAMETERS FOR STRESS/STRAIN CALCULATION

\begin{tabular}{|c|c|c|c|c|}
\hline \multirow[t]{5}{*}{$\mathrm{G} 2$} & layer & thickness [mm] & $\mathbf{E}_{\mathrm{s}} / \mathbf{E}_{\mathrm{w}}[\mathbf{M P a}]$ & $v_{s} / v_{w}$ \\
\hline & asphalt & 100 & $1500 / 5000$ & $0,45 / 0,25$ \\
\hline & CSM & 200 & 3359 & 0,25 \\
\hline & subbase & 350 & 80 & 0,35 \\
\hline & subgrade & $\infty$ & 50 & 0,4 \\
\hline \multirow[t]{5}{*}{$\mathrm{S} 2$} & layer & ticknes [mm] & Es / Ew [MPa] & $v_{s} / v_{w}$ \\
\hline & asphalt & 100 & $1500 / 5000$ & $0,45 / 0,25$ \\
\hline & CSM & 200 & 5643 & 0,25 \\
\hline & subbase & 350 & 80 & 0,35 \\
\hline & subgrade & $\infty$ & 50 & 0,4 \\
\hline \multirow[t]{5}{*}{ G4 } & layer & ticknes [mm] & Es / Ew [MPa] & $v_{s} / v_{w}$ \\
\hline & asphalt & 100 & $1500 / 5000$ & $0,45 / 0,25$ \\
\hline & CSM & 200 & 13890 & 0,25 \\
\hline & subbase & 350 & 80 & 0,35 \\
\hline & subgrade & $\infty$ & 50 & 0,4 \\
\hline \multirow[t]{5}{*}{$\mathrm{S} 4$} & layer & ticknes [mm] & Es / Ew [MPa] & $v_{s} / v_{w}$ \\
\hline & asphalt & 100 & $1500 / 5000$ & $0,45 / 0,25$ \\
\hline & CSM & 200 & 16980 & 0,25 \\
\hline & subbase & 350 & 80 & 0,35 \\
\hline & subgrade & $\infty$ & 50 & 0,4 \\
\hline
\end{tabular}

\section{Results and discussion}

Results of stress and strain analyses are presented in Appendix A. Analysis of stress and strain shown that asphalt layers are in the state of compression. These results are in accordance to [8]. Since compressive stress and strain is not critical for asphalt layers, it is not included in the further analyses.

Bottom surface of cement stabilized base layer is in the state of tension while upper surface of subgrade is in the state of compression independently on aggregate type, cement content or season. Critical stress and strain for cement stabilized base layer occurred in the plane paralleled to centre line of a road. For subgrade, critical stress and strain are vertical to its upper surface. So, critical stress and strain results are presented in Tables III and IV.
TABLE III. CRITICAL STRESS AND STRAIN FOR SUMMER SEASON

\begin{tabular}{|c|c|c|c|c|}
\hline $\begin{array}{c}\text { Mix } \\
\text { ID }\end{array}$ & $\begin{array}{l}\text { Stress-CSB } \\
\text { bottom } \\
\text { surface [MPa] }\end{array}$ & $\begin{array}{l}\text { Stress-sub- } \\
\text { grade upper } \\
\text { surface [MPa] }\end{array}$ & $\begin{array}{l}\text { Strain-CSB } \\
\text { bottom surface } \\
{[\boldsymbol{\mu m} / \mathbf{m}]}\end{array}$ & $\begin{array}{l}\text { Strain-sub- } \\
\text { grade upper } \\
\text { surface }[\boldsymbol{\mu m} / \mathbf{m}]\end{array}$ \\
\hline G2 & 0.5095 & 0.01365 & 122.7 & 251.5 \\
\hline S2 & 0.636 & 0.01206 & 90.41 & 217.3 \\
\hline G4 & 0.8931 & 0.009178 & 50.86 & 158.6 \\
\hline S4 & 0.9544 & 0.008533 & 44.34 & 146 \\
\hline
\end{tabular}

TABLE IV. CRITICAL STRESS AND STRAIN FOR WINTER SEASON

\begin{tabular}{|c|c|c|c|c|}
\hline $\begin{array}{c}\text { Mix } \\
\text { ID }\end{array}$ & $\begin{array}{l}\text { Stress-CSB } \\
\text { bottom } \\
\text { surface [MPa] }\end{array}$ & $\begin{array}{l}\text { Stress-sub- } \\
\text { grade upper } \\
\text { surface [MPa] }\end{array}$ & $\begin{array}{l}\text { Strain-CSB } \\
\text { bottom surface } \\
{[\boldsymbol{\mu m} / \mathbf{m}]}\end{array}$ & $\begin{array}{l}\text { Strain-sub- } \\
\text { grade upper } \\
\text { surface }[\boldsymbol{\mu m} / \mathbf{m}]\end{array}$ \\
\hline G2 & 0.4477 & 0.01112 & 107.5 & 206.2 \\
\hline S2 & 0.5584 & 0.009839 & 79.19 & 177.3 \\
\hline G4 & 0.8064 & 0.007807 & 45.94 & 134.4 \\
\hline S4 & 0.8714 & 0.00736 & 40.51 & 125.4 \\
\hline
\end{tabular}

\section{A. Influence of material characteristics on pavement stress state}

In Fig. 3 and 4, tensile stress for cement stabilized base layer (bottom surface) and compressive for subgrade (upper surface) are presented respectively, depending on mix type and season.

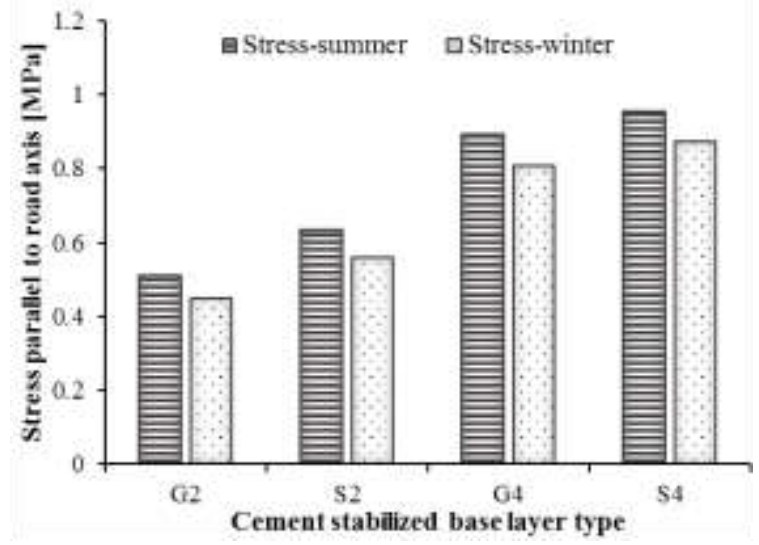

Figure 3. Horizontal tensile stress at the bottom surface of CSM

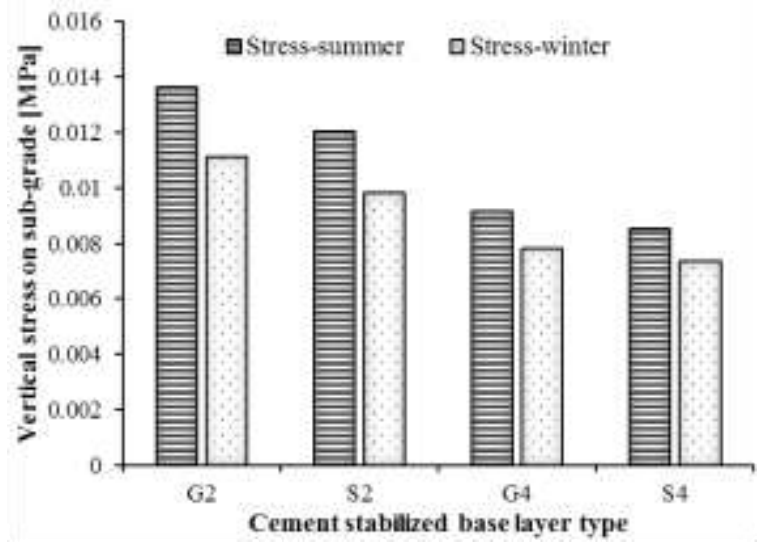

Figure 4. Vertical compessive stress at the upper surface of subgrade 
For cement stabilized base layer, horizontal tensile stress increases with cement and slag content. At the same time, vertical compressive stress on subgrade decrease with cement and slag content. This trend is apparent for both seasons.

At the bottom of CSM base layer, increasing cement content during summer season for mixes with gravel and mixes with slag results in $75.29 \%$ and $50.06 \%$ stress increase respectively. During winter season, increase is $80.12 \%$ and $56.05 \%$ for gravel and slag aggregate respectively. For CSM with $2 \%$ cement content during summer and winter season, stress increases with slag content for $24.83 \%$ and $24.73 \%$ respectively. For CSM with $4 \%$ cement content during summer and winter season, stress increases with slag content for $6.86 \%$ and $8.06 \%$ respectively.

At the top subgrade surface, increasing cement content during summer season for mixes with gravel and mixes with slag results in $32.76 \%$ and $29.25 \%$ stress decrease respectively. During winter season, decrease is $29.79 \%$ and $25.20 \%$ for gravel and slag aggregate respectively. For CSM with $2 \%$ cement content, during summer and winter season, stress decreases with slag content for $11.65 \%$ and $11.52 \%$ respectively. For CSM with $4 \%$ cement content, during summer and winter season, stress decreases with slag content for $7.03 \%$ and $5.73 \%$ respectively. Generally, adding steel slag to cement stabilized mixes with $2 \%$ and $4 \%$ cement content result in subgrade stress decrease by about $11 \%$ and $6 \%$ respectively.

Increasing cement content significantly affects the stress state of the mixture with steel slag. The reason may be a specific behaviour and different influences on strength development for mixes with steel slag as described in [9]. Increased modulus of elasticity with cement content is a result of an increase in material strength. With higher compressive strength, material is able to take a larger portion of traffic load relieving subgrade. The result is decrease in subgrade stress as shown in Fig. 4.( in average for 29.25\%).

During winter season, lover stresses occur in CSM base layer and subgrade as a result of asphalt characteristics. During summer season, stiffness and load bearing capacity of hot asphalt layers decreases, due to asphalt binder softening under high temperatures.

\section{B. Influence of material characteristics on pavement strain state}

In Fig. 5 and 6, tensile strain for cement stabilized base layer (bottom surface) and compressive for subgrade (upper surface) are presented respectively, depending on mix type and season.

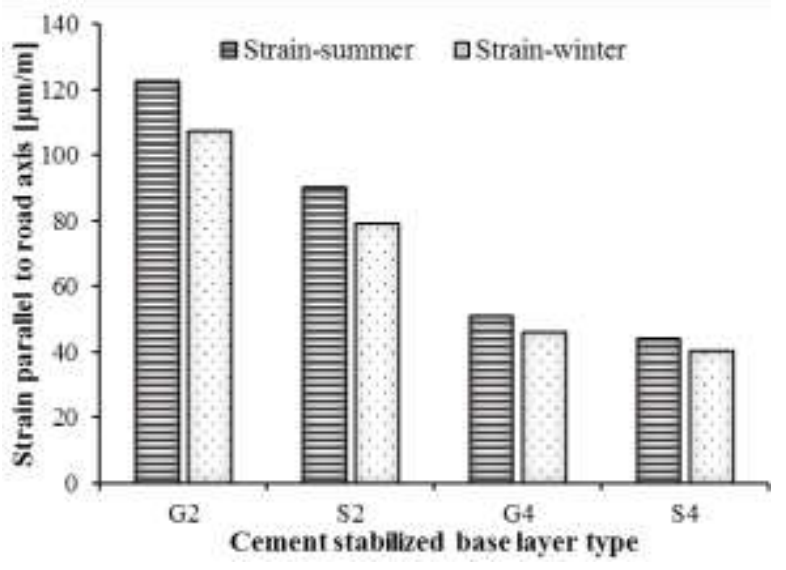

Figure 5. Horizontal tensile strain at the botom surface of CSM base layer

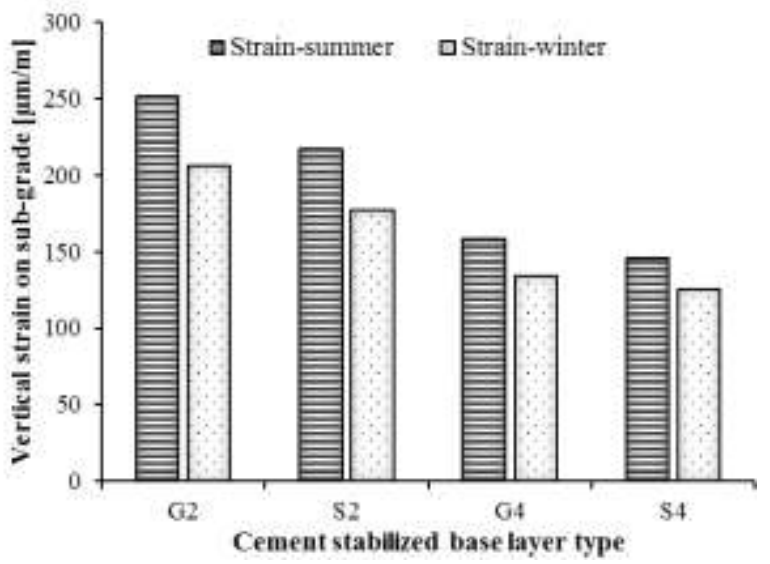

Figure 6. Vertical compessive strain at the upper surface of subgrade

For cement stabilized base layer, horizontal tensile strain parallel to centre line of a road decreases with cement and slag content. The same trend is valid for vertical compressive strain at the top subgrade surface, regardless the season.

At the bottom of CSM base layer, increasing cement content during summer season for mixes with gravel and mixes with slag results in $58.55 \%$ and $50.96 \%$ strain decrease respectively. During winter season, decrease for gravel and slag aggregate is $57.27 \%$ and $48.84 \%$ respectively. For CSM with $2 \%$ and $4 \%$ cement content, strain decreases with slag content for nearly $26.3 \%$ and $12 \%$ respectively.

At the top subgrade surface, increasing cement content during summer season for mixes with gravel and mixes with slag results in $36.94 \%$ and $32.81 \%$ strain decrease respectively. During winter season, decrease is $34.82 \%$ and $29.27 \%$ for gravel and slag aggregate respectively. For CSM with $2 \%$ cement content, during summer and winter season, strain decreases with slag content for $13.60 \%$ and $14.02 \%$ respectively. For CSM with $4 \%$ cement content, during summer and winter season, strain decreases with slag content for $7.95 \%$ and $6.70 \%$ respectively. Strain decrease with cement content is also in accordance to [10]. 
Proc. of the Third Intl. Conf. on Advances in Civil and Structural Engineering - CSE 2015 Copyright $(\odot$ Institute of Research Engineers and Doctors, USA .All rights reserved.

ISBN: 978-1-63248-057-6 doi: 10.15224/ 978-1-63248-057-6-46

As discussed earlier in the text, increased modulus of elasticity results an increase in material strength. With higher compressive strength, material is able to take a larger portion of traffic load relieving subgrade. Result is strain decrease. Tensile and compressive strain decrease during winter season is influenced by asphalt characteristics. Higher modulus of asphalt for lower temperatures during winter season result in strain decrease [33].

\section{Conclusion}

Based on laboratory determined material characteristics and conducted analytical stress-strain analyses, the following conclusion can be made:

- Steel slag stabilized mixes have higher dynamic modulus of elasticity then gravel stabilized mixes

- Cement stabilized material as base layer has significant impact on pavement stress-strain state

- Stress on CSM base layer level increases with cement and slag content, regardless of the season

- Stress on subgrade level decrease with cement and slag content regardless of the season

- Strain decrease with cement and slag content, regardless of the season

- Pavement stress and strain state are highly influenced by season, due to the asphalt characteristics.

Due to all results and analyses it can be concluded that adding steel slag to cement stabilized base layer can be beneficial in terms of decreasing stress and strain at the subgrade level. Adding steel slag to cement stabilized mixes with $2 \%$ and $4 \%$ cement content result in subgrade stress decrease by about $11 \%$ and $6 \%$ respectively and strain decrease by about $13 \%$ and $7 \%$ respectively. This can be beneficial in terms of pavement thickness reduction and saving financial resources. Also, it opens the possibility for the construction of pavements on weaker soil. To verify these findings, additional field test should be performed.

\section{References}

[1] M.N.S. Hadiand and B.C. Bodhinayake, "Non-linear finite element analysis of flexible pavements" in Advances in Engineering Software, 2003, 34, pp. 657-662.

[2] Y. Cai, A. Sangghaleh and E. Pan, "Effect of anisotropic base/interlayer on the mechanistic responses of layered pavements" in Computers and Geotechnics, 2015, 65, pp. 250-257.

[3] A.E.A.E.-M. Behiry, "Fatigue and rutting lives in flexible pavement" in Ain Shams Engineering Journal, 2012, 3(4), pp. 367-374.

[4] A. Mokhtari and F.M. Nejad, "Mechanistic approach for fiber and polymer modified SMA mixtures" in Construction and Building Materials, 2012, 36, pp. 381-390.

[5] J. Judycki and P. Jaskula, "Structural Design and Sensitivity Analysis of Semi-Rigid Pavement of a Motorway" in Engineering Journal, 2012, 16(4), pp. 117-126.

[6] D. Breysse, "Nondestructive evaluation of concrete strength: An historical review and a new perspective by combining NDT methods" in Construction and Building Materials, 2012, 33, pp. 139-163.

[7] A. Benouis and A. Grini, "Estimation of concrete's porosity by ultrasounds" in Physics Procedia, 2011, 21, pp. 53-58.

[8] S. Lijun and W. Xinwu, "Analysis of Load Stress for Asphalt Pavement of Lean Concrete Base" in Physics Procedia, 2012, 24, pp. 404 - 411.

[9] I. Barišić, S. Dimter and T. Rukavina, "Strength properties of steel slag stabilized mixes" Composites: Part B, 2014, 58, pp. 386-391.

[10] M.A. Lav and A.H. Lav, "Effects of stabilization on resilient characteristics of fly ash as pavement material" in Construction and Building Materials, 2014, 54, pp. 10-16.

Appendix A: Detailed results of stress and strain analises by BISAR softwere

\begin{tabular}{|c|c|c|c|c|c|c|c|}
\hline \multicolumn{2}{|c|}{ SUMMER/WINTER } & \multirow{2}{*}{$\begin{array}{c}\text { Stress [MPa] } \\
\begin{array}{c}\text { Parallel to } \\
\text { centre line }\end{array} \\
\end{array}$} & \multirow{2}{*}{$\begin{array}{c}\text { Stress [MPa] } \\
\text { Perpendicular } \\
\text { to centre line }\end{array}$} & \multirow{2}{*}{$\begin{array}{c}\text { Stress [MPa] } \\
\text { Vertical }\end{array}$} & \multirow{2}{*}{$\begin{array}{c}\text { Strain }[\mu \mathrm{m} / \mathrm{m}] \\
\begin{array}{c}\text { Parallel to centre } \\
\text { line }\end{array} \\
\end{array}$} & \multirow{2}{*}{$\begin{array}{c}\text { Strain }[\mu \mathrm{m} / \mathrm{m}] \\
\begin{array}{c}\text { Perpendicular to } \\
\text { centre line }\end{array}\end{array}$} & \multirow{2}{*}{$\begin{array}{r}\text { Strain }[\mu \mathrm{m} / \mathrm{m}] \\
\text { Vertical }\end{array}$} \\
\hline $\begin{array}{c}\text { Mix } \\
\text { ID }\end{array}$ & Possition & & & & & & \\
\hline \multirow{3}{*}{ G2 } & $\begin{array}{l}\text { bottom } \\
\text { asphalt }\end{array}$ & $-0,435 /-0,046$ & $-0,427 /-0,048$ & $-0,504 /-0,409$ & $-10,680 / 13,740$ & $-2,867 / 13,090$ & $-77,430 /-77,150$ \\
\hline & $\begin{array}{l}\text { bottom } \\
\text { CSM }\end{array}$ & $0,510 / 0,448$ & $0,416 / 0,369$ & $-0,028 /-0,022$ & $122,700 / 107,500$ & $87,860 / 78,110$ & $-77,020 /-67,340$ \\
\hline & $\begin{array}{l}\text { top } \\
\text { subgrade }\end{array}$ & $-0,001 /-0,001$ & $-0,002 /-0,001$ & $-0,014 /-0,011$ & $99,650 / 81,810$ & $86,590 / 71,860$ & $-251,500 /-206,200$ \\
\hline \multirow{3}{*}{ S2 } & $\begin{array}{l}\text { bottom } \\
\text { asphalt }\end{array}$ & $-0,496 /-0,187$ & $-0,487 /-0,174$ & $-0,531 /-0,453$ & $-25,330 /-5,987$ & $-16,400 /-2,743$ & $-59,130 /-72,580$ \\
\hline & $\begin{array}{l}\text { bottom } \\
\text { CSM }\end{array}$ & $0,636 / 0,558$ & $0,527 / 0,465$ & $-0,023 /-0,018$ & $90,410 / 79,190$ & $66,250 / 58,550$ & $-55,560 /-48,610$ \\
\hline & $\begin{array}{l}\text { top } \\
\text { subgrade }\end{array}$ & $-0,001 /-0,001$ & $-0,002 /-0,001$ & $-0,012 /-0,010$ & $83,480 / 67,960$ & $73,510 / 60,310$ & $-217,300 /-177,300$ \\
\hline \multirow{3}{*}{ G4 } & $\begin{array}{l}\text { bottom } \\
\text { asphalt }\end{array}$ & $-0,528 /-0,293$ & $-0,521 /-0,273$ & $-0,562 /-0,515$ & $-26,860 /-19,180$ & $-20,250 /-14,270$ & $-60,290 /-74,720$ \\
\hline & $\begin{array}{l}\text { bottom } \\
\text { CSM }\end{array}$ & $0,893 / 0,806$ & $0,760 / 0,685$ & $-0,015 /-0,013$ & $50,860 / 45,940$ & $38,850 / 34,980$ & $-30,820 /-27,750$ \\
\hline & $\begin{array}{l}\text { top } \\
\text { subgrade }\end{array}$ & $-0,001 /-0,001$ & $-0,002 /-0,001$ & $-0,009 /-0,008$ & $57,540 / 48,490$ & $51,800 / 43,740$ & $-158,600 /-134,400$ \\
\hline \multirow{3}{*}{ S4 } & $\begin{array}{l}\text { bottom } \\
\text { asphalt }\end{array}$ & $-0,528 /-0,299$ & $-0,522 /-0,280$ & $-0,567 /-0,527$ & $-25,180 /-19,530$ & $-19,300 /-14,780$ & $-63,280 /-76,340$ \\
\hline & $\begin{array}{l}\text { bottom } \\
\text { CSM }\end{array}$ & $0,954 / 0,871$ & $0,816 / 0,743$ & $-0,014 /-0,012$ & $44,340 / 40,510$ & $34,180 / 31,050$ & $-26,850 /-24,440$ \\
\hline & $\begin{array}{l}\text { top } \\
\text { subgrade }\end{array}$ & $-0,001 /-0,001$ & $-0,002 /-0,001$ & $-0,009 /-0,007$ & $52,250 / 44,650$ & $47,26040,420 /$ & $-146,000 /-125,400$ \\
\hline
\end{tabular}

